\title{
Beyond compliance: teacher education practice in a performative framework
}

Robert Lawy University of Exeter UK

Michael Tedder University of Exeter UK

\begin{abstract}
The further education (FE) sector in the UK has seen a reform of teacher training with the introduction of qualifications designed to meet the professional needs of people in different teaching or training situations across the sector. The assumption of the new system is that workforce issues can be resolved through the regulation and control of teacher performance using documented 'standards' and with subject-specific mentoring. Using data from a research study, the authors argue against the performative nature of the reformed system and in favour of pedagogical mentoring to support professional formation and development throughout the sector. The aim of the paper is both to exemplify the performative shift in the FE sector as part of a broader move in the sector towards increased control, surveillance and accountability but also to demonstrate opportunities within the reformed structure for a new and critical engagement in policy and practice.
\end{abstract}




\section{Introduction}

In recent years in the UK there has been an increased recognition of the importance of the further education (FE) sector. This sector embraces adult and community learning (ACL), work-based learning (WBL) and the voluntary sector and comprises both fulltime and part-time courses and training beyond the school leaving age (currently age 16 in the UK) [1] and below degree level. Since 2001 there has been a statutory requirement for all teachers in this sector to undertake a formal teacher training programme that is appropriate to their role (see Nasta 2007). Many of those undertaking training work in a part-time capacity within vocational areas where degree level qualifications are not a pre-requisite for entry into the profession (for example, catering and hairdressing). Such differences contrast with the more straightforward situation in the compulsory (school) sector where graduate teachers are required to undertake a programme of certified and accredited training prior to taking up their employment.

Although the shift from voluntarism to legal regulation of initial teacher training is a relatively new phenomenon in the sector, the regularising of programmes of initial training based on the assessment of 'standards' has been a part of the lexicon of teacher education in the school sector for a number of years (DfE 2002, 2003). It was only a matter of time before it was formalised in the articulation of the FE National Training Organisation standards (FENTO 1999).In the foreword to Further Education Workforce Reforms (LLUK 2007), Bill Rammell (Minister of State for Lifelong Learning, Further and Higher Education), stressed the need for a workforce in further education that is 'thoroughly professional and highly skilled'. Such aspirations have subsequently been re-emphasised in the revised version of the workforce strategy for the FE sector (LLUK 2009). 
In the last six years a range of differentiated qualifications has been introduced into the sector. These were ostensibly designed to meet the various professional needs of practitioners, including those non-graduates who teach craft-related subjects and undertake a training role. The qualifications include: 'Preparing to Teach in the Lifelong Learning Sector Award' (PTLLS Award); 'Certificate in Teaching in the Lifelong Learning Sector' (CTLLS); 'Diploma in Teaching in the Lifelong Learning Sector' (DTLLS). Aside from these awards, there continue to be Postgraduate Certificate in Education programmes (PGCE) which are validated at different levels and recognised within the National Qualifications Framework that sets out a framework of levels for the recognition of qualifications in England, Wales and Northern Ireland.

The underlying assumption of these new teacher qualifications is that many problems in the FE sector have been due to poor teaching and inadequate training, furthermore that these issues can be resolved through the introduction of more regulation and control with a tight and prescriptive set of standards backed up by a strong and robust regulatory framework. Under this schema, it is the achievement of the standards rather than a critical engagement with them that is important. Here, standards are a fixed outcome or point of reference rather than an input into a dialogue about different teacher practices. Two survey reports from the Office for Standards in Education (Ofsted 2003, 2006) confirmed huge variability in how the standards have been implemented following their introduction (FENTO 1999). Some of the main criticisms were directed towards the lack of systematic mentoring and support in the workplace: 
The current system of FE teacher training does not provide a satisfactory foundation of professional development for FE teachers at the start of their careers. While the tuition that trainees receive on the taught elements of their courses is generally good, few opportunities are provided for trainees to learn how to teach their specialist subjects, and there is a lack of systematic mentoring and support in the workplace. (Ofsted, 2003, 2)

As a consequence, Lifelong Learning UK (LLUK) [2] constructed a 'new' and revised set of standards and a stronger regulatory framework, in which trainees would be supported 'either by line managers, subject experts or experienced teachers in related curriculum areas' (DfES 2004, para 3.6). By 2006 Ofsted was able to report an improvement in the standard and quality of teaching. However, commenting on the systems and structures of accountability, it was noted that 'the attention given to assessing the procedures for assuring the accuracy of the assessment of trainees' teaching performance still lack rigour' (Ofsted 2006, 2).

Elsewhere, Lawy and Tedder (2009a) have demonstrated the impact of the changes in regulation on the practices and understanding and agency of teacher educators whose formal role is to ensure the delivery and assessment of the new standards. Although some of the teacher educators felt they had less control over the content and delivery of their programmes, others (commonly those new to the profession) have found new ways of articulating and expressing their agency. In this paper we report on other yet related aspects of the same research project that was completed in January 2009, concerning the use of Individual Learning Plans (ILPs) and mentoring in the reformed teacher training. 
The paper is organised into five sections. In the second section we contextualise the issue of changing teacher education policy and practice in the FE sector as part of a performative shift in the public sector as a whole towards accountability. In the third section we describe the methodology and the interpretative and biographical methods that we used to explore the understandings and meaning of the tutors, managers and trainees. In so doing we focus upon the twin issues of mentoring and the ILPs that we utilise to exemplify the issues raised. In the fourth section, we discuss key findings that emerged from our interviews. In the concluding section of the paper we argue for a pedagogical mentoring role that is developmental and experiential and is focused upon issues of curriculum, pedagogy, context and history. We reject the implicit reductionism of the current scheme and suggest that concerns with outputs, achievements and skill acquisition, however defined, as coaching or assessment, can be used as a basis for an engagement between student teachers, tutors and mentors. We argue for an outlook that moves beyond compliance and the performative criteria that underpin it, towards an approach where teacherpractitioners can engage in a reflexive and professional engagement with the underlying assumptions, grammars and standards of professional practice. Such an approach would enable teacher-practitioners to meet with the Ofsted and other requirements but in a way that is critical and not solely concerned with issues of compliance.

\section{Context}

In this second section of the paper we are concerned to locate the development of teacher education practices within a broader historical and contextual framework. We are concerned with what Ball $(2003,2008)$ refers to as policy technologies: 
[These] involve the calculated deployment of forms of organisation and procedures and processes, and disciplines or bodies of knowledge to organise human forces and capabilities into functioning systems. (Ball 2008, 41)

Policy technologies should not be viewed individually; rather they should be viewed as part of a broader shift in the public sector towards unified models of practice. These technologies reconstruct and prescribe social relationships and serve to define symbolic and material meanings of individual subjects. The education sector has not been alone in coming to terms with profound change (Clarke and Newman 1997). Over the last two decades competition and marketisation have become a mantra within the public sector, with internal markets systems and structures to ensure private sector accountability within a public domain. Performativity is a particular policy technology or regime of accountability that 'employs judgements, comparisons and displays as a means of control, attrition and change' (Ball 2008, 49) to achieve these purposes. These changes have impacted at an institutional level on the structure, organisation and governance of FE colleges and universities. Moreover, they have impacted on teacher educators (trainers) and student teachers (trainees) as responsibility for the curriculum and its organisation has been ceded to managers and external bodies (see Dale 1989).

The 1992 Further and Higher Education Act incorporated FE colleges and removed them from local authority control. At that time 'market' metaphors came to dominate college policies and business practices were perceived as ideal models for college operation (Ainley and Bailey 1997). The sector was faced with pressures to reduce costs and increase accountability and efficiency in order to survive. FE 
colleges no longer received block grants but were funded on the basis of numbers, with a focus on retention and achievement rates. Following incorporation, colleges immediately faced a new and competitive market where, in order to survive, they needed to achieve effectiveness and efficiency at a lower cost in order to be competitive.

In the last decade this drive towards competition has resulted in a rapid expansion of the number of people in the FE sector, particularly within the 16-18 age range. Figures from the Learning and Skills Council (LSC) [3] note that by 2005, there were more than 100,000 additional 16 - to 18 -year-olds in full-time education compared to 1997; the numbers of young people on apprenticeships had tripled, and over a million adults had registered for basic skills courses (LSC 2005). The increased costs associated with this expansion of numbers resulted in the systematic erosion of the pay and conditions of service of lecturing staff. It changed the way that students were (re)constructed as consumers/clients and learners, and courses are delivered and managed with a manifest emphasis in the sector on individualised provision. This new disciplinary logic, and the concomitant surveillance, regulation and control, is articulated as part of the mantra of 'meeting learner needs'. Within this logic the provision of mentors and individual learning plans to support learners, are presented as being incontestably beneficial.

The performative criteria and judgements and systems that have increasingly been used to measure the effectiveness and efficacy of practice have spawned a proliferation of managers with the responsibility of ensuring that targets are met and that staff engage in those practices that achieve those goals. Increasingly professional judgements are subject to surveillance and self-surveillance (Foucault 1977) with teacher educators and managers, teachers and trainees adhering to the requirements of 
Ofsted inspection regimes and other performative systems and routines, even though they held deep reservations about their efficacy. This contrasts with the post-war settlement (broadly up until the 1970s) where teachers were generally trusted to manage and determine their own teacher practices. Teacher work in both the school and FE sector was a 'legitimated' sphere of professional activity in which the idea of professionalism was founded upon notions of autonomy and independence without outside interference.

Other researchers have analysed the strategies used by FE staff to retain some control within processes of change. Shain and Gleeson (1999) describe teacher responses to the increasingly managerial culture of the 1990s, characterising them as showing rejection and resistance, compliance or strategic compliance. In a parallel work, Gleeson and Shain (1999) commented on the responses of middle managers to their increasing managerial role. It was observed how such managers mediate the pressures made on them and may manifest willing or unwilling compliance with the direction of change (see also Colley et al. 2007; Steer et al. 2007).

Avis (2005) draws attention to the contradiction between the performative demands and the expectations of policy and assumptions that underpin it:

Performativity, through its chain of targets and accountability operates within a 'blame culture' where accountability becomes a means by which the institution can call to account its members. In many respects perfomativity is reminiscent of Fordist work relations in as much as the worker is tightly surveilled, with attempts to render transparent the details of practice. Performance management sits well with low trust .. [and] is at odds with current strictures surrounding the knowledge economy, which emphasise 
fluidity, non-hierarchical team work and high trust relations linked to the ongoing development of human, intellectual and social capital. (Avis 2005, 212)

The performative demands of policy have thus created conditions whereby tutors and managers responsible for policy implementation construct fabrications that is organisational representations which meet auditable and accountability frameworks (Edward and Coffield 2007). Learning relationships between tutors and students, including trainee teachers, are aligned through these systems and structures: 'guidance, combined with a core curriculum, the demands of audit and inspection, positions tutors uncomfortably as active mediators between student experience and the policy discourse' (Hamilton 2009, 221).

In the next section we describe the methodology and approach of our research focusing upon the issue of mentoring and the use of ILPs which are central to the newly constructed FE teacher training lexicon. We show how performative policies of surveillance, control and accountability have been manifested through the use of mentoring and ILPs. Yet, we also show that policy itself is enacted and is described rather than prescribed and always and necessarily open to interpretation.

\section{Methodology and Methods}

The research project was part of a series funded by the Quality Improvement Agency (QIA) via Centres for Excellence in Teacher Training (CETTs)[4] and was undertaken in the South West of England. It was commissioned to study the impact and effectiveness of mentoring and individual learning plans (ILPs) in the re-engineered training programmes that now operate. The project was primarily focused upon FE 
sector provision but also included organisations involved in adult and community learning (ACL) and work-based learning (WBL) (Lawy and Tedder 2009b).

The principal data collection method comprised semi-structured interviews and twenty-eight interviews were undertaken in the early months of 2008. The research team collected rich qualitative data from ten trainees, from nine teacher educators who fulfil roles as tutors and/or mentors in programmes and also from nine managers, some working in FE colleges and some in other community organisations [5]. We recorded five interviews with managers employed in colleges who had responsibility for the quality of teaching and learning in their institutions. The extent of their experience and involvement in teacher education varied: some held line manager responsibility for the programme in their college or for a team of teacher trainers but arrangements varied from college to college and, indeed, varied for each individual from year to year. We also recorded and transcribed interviews with three managers working in ACL contexts. Seven of the tutors interviewed were collegebased and were involved in PGCE and other initial teacher training programmes. Most tutors had a range of responsibilities in other programmes, not solely ITT courses, while one was a programme manager in another field and mentored trainees on placement in her section. Two tutors worked for a county council, training teachers of adults in community settings for a PTLLS award. The trainees we interviewed were studying a range of programmes at different levels (see Lawy and Tedder 2009b).

The analysis used a life history or biographical methodology in order to locate the narratives of interviewees within a wide personal and social context (Alheit 2005; Tedder and Biesta 2009). The assumption of the research was that there would be stories to be told within the community of practice (Lave and Wenger 1991), from the 
managers, tutors and the trainee teachers about their practices and the mechanisms that they adopted to make sense of, and shape their worlds.

The interviews lasted between 45 minutes and two hours and all were taperecorded and fully transcribed. Each began with an explanation of the ethical protocols and the interviewees were asked to sign a consent form that clearly stated that the research data would be treated as confidential, and that they had the right to withdraw from the research at any stage. All the respondents were offered the opportunity to check the accuracy of the transcripts from their interviews.

The interviewees were asked to describe themselves, their work and their organisation. They were asked: 'Can you tell me about yourself and how you come to be in your current role?' Such questions helped reduce any tension that might have been present and providing a rich source of important biographical and contextual information. Later questions enabled the interviewees to go beyond answering narrowly technical questions about planning or about mentoring practices and to convey something of what such experiences meant for them personally and for their professional formation. They included such questions as: 'What did you do?'; 'Can you give me an example of ... ?'; What sense did you make of this experience?' All these questions were deliberately open-ended (though framed within the research parameters) to allow for a deeper exploration and understanding than would have been possible using closed questions.

It is important to emphasise that our interview transcripts represented the first step in a two stage process. Although we were seeking an understanding of the engagements, actions and practices of the interviewees, including the problems and concerns of their daily lives, we were also concerned to move beyond their interpretations, to explore and understand the underlying issues that caused them to 
self-present and act in particular ways. To put this another way, we wanted to locate and interpret their individual narratives within a broader framework. As Shutz (1967) explains:

The thought objects constructed by the social scientist ... have to be founded upon the thought objects constructed by the common-sense thinking of men, living their daily life within the constructs of the social world. Thus the constructs of the social sciences are constructs of the second degree, ... constructs of the constructs made by the actors on the social scene. (Schutz, $1967,59)$

In the early phase of the research the team undertook some scoping of the field of practice beyond the FE sector which allowed us to increase our knowledge and understanding and with the framing of our questions to the respondents. The research team met regularly for discussion through the research process. These meetings provided an opportunity for discussion, and to theme and code data that were continuously subject to an iterative process of interpretation and reinterpretation. As part of this process, we met with practitioners and key stakeholders where we were able to present our findings and open them out for discussion.

\section{Findings}

In this section we present some of our key findings illustrated by cases selected from our overall sample. It needs to be emphasised that the findings are not statistically representative of mentoring practices within further education; the discussion uses the perspectives of our respondents as tutors, managers and trainee teachers, to explore aspects of the present training framework, how particular policy technologies 
function. Our interviewees gave us insights into how training policies are operating for them in practice. Their stories of professional learning reveal the way that policies are mediated and how practices are rationalised in the light of personal experience.

Two related tensions emerged from our interviews with managers and tutors that we wish to emphasise. The first was the tension between developmental and judgemental aspirations in mentoring and the use of ILPs. Following the introduction of the FENTO standards, the Association of Colleges (AoC) and FENTO commissioned a set of materials to 'improve the quality of teaching and learning' (AoC and FENTO 2001, 1) and develop excellence through appropriate mentoring systems and strategies. The ensuing publication, Mentoring Towards Excellence followed detailed consultation with 700 students, and more than 70 teachers and managers in 29 colleges. It was assumed that all teachers in the sector stood to benefit from 'good' mentoring relationships and that these should be formative, supportive and developmental. Yet a short time later, following the intervention of Ofsted and the publication of Equipping our Teachers for the Future (DfES 2004), the approach towards mentoring changed substantially towards an essentially 'off the shelf' schoolbased and judgemental model of practice where the focus is upon assessment and measurable accountability in relation to a set of standards. Although the participants in our research were not always aware of this shift in focus, all were conscious of the implications of the shift towards judgement and accountability and the corresponding impact on mentor/mentee relationships (see Tedder and Lawy 2009).

The second tension concerns professional practice and the mismatch between the value system and commitment to public duty and service of further education staff, where the emphasis is upon the professional formation and identity within a community of practice (see e.g. Harrison et al. 2003; Gleeson et al. 2005 see also 
James and Biesta 2007), and the individualistic values and approach associated with the performative systems. The Institute for Learning (IfL) is the body responsible for the professional formation of teachers in the further education and skills sector, and governs their licence to practice in relation to a set of externally prescribed LLUK standards. Qualified teachers are required to engage in a 30 hour programme for fulltime teachers and trainers of continuing professional development (pro-rata for those who work part-time, with a minimum number of 6 hours) that is focused on ‘improving and broadening relevant [subject specific] knowledge and skills' (IfL 2009,3). Here the assumption is that there is broad agreement about what constitutes professional practice, particularly with regard to the specific subject character and focus of their professional development. Julia Evetts $(2005,9)$ has shown how these and other forms of 'organizational professionalism' have been used as a control mechanism promoting occupational change through micro-level control over professional practice. This is achieved through 'a disciplinary logic which inscribes "autonomous" professional practice within a network of accountability and governs professional conduct at a distance' (Fournier 1999, 280). By way of contrast 'occupational professionalism' is a discourse constructed within professional occupational groups which themselves set out their own guidelines and codes of professional conduct and ethics. It depends on common and lengthy systems of education and vocational training and the development of strong occupational identities and work cultures (Evetts 2005, 9; Colley et al. 2007; see also James and Biesta 2007).

Two of the managers that we interviewed (Angela and Andrew) had been participants in the research that led to Mentoring Towards Excellence (AoC and FENTO 2001). Their experience appeared to make a significant contribution to the 
policies and practices pursued by their respective colleges and each articulated considered and contrasting views about mentoring in initial teacher training.

Andrew had many years' experience of teaching in a subject specialism as well as in teacher education before accepting a role in quality management in his college. He outlined some of the range of functions that mentoring encompasses, including an advocacy role on behalf of a trainee within the institution where he or she works:

[Our college mentors] had a number of things they had to do including informal classroom observation, being available to the mentee, make sure that they were comfortable in their subjects with the professionalism, make sure they got the development opportunities as they needed and the quid pro quo was the person doing the mentoring would be remitted for twenty, twentyeight, twenty-five hours of their eventual time. (February 2008)

Of the LLUK standards he said:

the new standards have made absolutely clear that [pause] to reach a professional level of teaching one's own subject and mediating one's own subject for learning is an important strand ...(a process) supported by a proper mentoring system, struck one as both overdue and very necessary. (February 2008)

Andrew was sympathetic to the Ofsted expectation of addressing subjectspecific issues through mentoring, but was not convinced by the need for such an approach for teachers with substantial experience in their own subject areas. He viewed mentoring as a tool for addressing subject specific issues, but also and 
necessarily, in the case of all new teachers, for the development and understanding of pedagogic practice: 'they understand their subject very well... better than actually sometimes they understand teaching and learning.'

Our second experienced manager, Angela was keen to emphasise what she saw as a critical distinction between mentoring and subject coaching:

[A] coach is one who says you know maybe, 'This is how it, this is how it ought to be done, you know, give it a try and see,'... Whereas a mentor is someone who says, 'Well how do you think you will best achieve that?' ... their role isn't, isn't to mark your work or, you know, their role is to prompt your thoughts and to - and therefore to, to get you to come to the right conclusions, to draw that conclusion on your own. (February 2008)

Whereas Angela saw the role of a coach as ensuring that the mentees could achieve a set of pre-specified goals and outcomes, she saw the role of a mentor as more broadly concerned with encouraging a critical engagement in practice through the development of reflective and reflexive qualities.

Claire was another manager with more than two decades of experience in a third college in our survey. She emphasised the importance of a friendly relationship in mentoring that should be clearly separate from a role of assessing performance to satisfy requirements for surveillance and formalised judgement-making - an instance of what Colley (2003), refers to as a shift from a dyadic to a triadic mentoring relationship: 
[G]oing back to the mentoring, yep you need a buddy. You need that colleague; you need somebody who can say, 'Well, that was rubbish wasn't it?' You say, 'Yea it was rubbish!' You also need someone to keep you going if, you know, to jolly you along and say, 'Oh, keep, you know, nearly halfterm' sort of thing. Yes you need the professional standards, we need somebody who's going to make a judgement on you and that's my linemanager. (February 2008)

Emphasising this developmental aspect of mentoring, one of the tutors we interviewed, Gill, recalled the support she had received from a respected head of science and emphasised the importance of that role model for her own development and practice:

I had a really good manager at [my previous college]. I mean a really superb manager who managed $m e$ as a teacher in the very best possible way you could ever do. He challenged me, he set me targets, constantly monitored what I was doing, gave me huge amounts of feedback, very detailed feedback about what I was doing and how I could improve, allowed me to use him as a sounding board. (February 2008 emphasis in original)

She continued:

[Mentoring] is about challenging. It's not about being a friend. It's not about placating people and saying, 'Yes you're wonderful and you know, how can I help?' It's about challenging... and about being critical and being, you know, 
'Have you thought about, what do you mean by that?' ... Opening doors but not pushing people through them [laughs]. (February 2008)

Janet was another who described how other people had been inspirational and hence crucial to her development. She recalled a friendly relationship with a 'course buddy' during her teacher training. She sought to bring that sense of productive informality into the current and ongoing relationships with her students. She achieved this by setting the formal requirements of the mentoring role apart from what she considered to be the more important informal support that she wanted to provide for her students.

If we're talking, if we're talking about the actual subjects, the, the, you know, the course that we're teaching, that is something that I consider as part of my role as course manager... I do that with all the lecturers, so I don't even think about it as being mentoring. ... so we are always talking about, you know, how they're getting [on] with the unit and what this bit of paper, what this bit of writing means, you know, what they're expected to do here. (April 2008)

A concern for standards was common among our interviewees, but rarely did they refer to the standards expressed in written documents. Dawn, for example, trained and practised for many years as a nurse in the National Health Service before joining her college. She talked about the importance of 'standards' for trainees - not as a set of prescribed standards that trainees are expected to achieve but rather as a set of expectations about their work. 
Whilst all of our interviewees were aware of the need to ensure the use of ILPs as a document of record, many at the time of the introduction of the new standards in 2008, were not aware of its use as a planning or prospective document with a plan of activities for trainees, with a time schedule for the achievement of the standards. Notwithstanding this, they were familiar with the basic techniques expected for ILPs, such as undertaking initial assessment, SWOT analysis, action planning and target setting. However, as Maggie confessed they varied in the importance they attached to these demands:

If I'm honest, I didn't really look at the standards at all, I was looking at the ILP itself and referring it back to the individuals... where people were stuck then having general discussions about it and, you know, kind of prompting thoughts with other people. (March 2008)

None of the tutors that we interviewed was comfortable with the idea of ILPs as only an assessment tool to measure the achievement of national standards. Some, like Maggie, saw the performative demands that they were being subjected to as second order activities yet they frequently found themselves focusing more attention on ensuring these mundane activities than on their actual teaching (Ball 2003). Others like Christopher felt that ILPs could be a useful tool. However, he considered trainees were 'filling out' their ILP forms and was not at all sure they were 'using' them in the way that was intended. He doubted that there was sufficient follow-up to the plans and reviews of progress for the ILPs to become meaningful.

Kate, a part-time PGCE trainee with experience in the field of arts and textiles, had little commitment to her ILP: 
I think ILP's are a funny thing anyway. I think they're ultimately a bit of a waste of time, but I kind of - I know why we have to do them. It's all to do with getting money... we haven't done hardly anything 'cos I think my mentor thinks they're a bit of a waste of time as well. (February 2008)

She commented on the sceptical attitude from her mentor that appeared to be part of a wider staffroom culture in the college:

This attitude may have come from other people saying, 'Oh load of rubbish'. You know, I work in a, I work in a staffroom, I hear people talking about stuff, 'Blah, blah, blah, bloody ILPs' whatever. (February 2008)

Trainees remarked on how important it had been for them to work collegially and expressed appreciation of colleagues and line-managers who were supportive of their professional development. Naomi explained how she was also able to draw upon advice and support from colleagues other than her mentor, who was also her line manager:

We have somebody in the office who's actually a college, ex-college lecturer tutor, in fact there's two people, and so they're very good. So if it's to do with college, and we're a bit sort of unclear about something, we usually talk to them... (March 2008) 
All of the trainees recognised the importance of their ILPs and the link to the national standards but many did so in a functional way. None saw the documents as anything other than a record to enable supervision and assessment by their tutors. ILPs were seen very much as a mechanism for recording and monitoring the formalised discussions and achievements that had taken place in the formal mentoring meetings between trainees and their mentors rather than the representation of a confidential dialogic discourse. There was frustration that this process was essentially bureaucratic and at least partially removed from the practical concerns of the trainees as developing teachers. As Ian explained:

I think the, the value of [the standards] will perhaps kick in, you know, as everything else becomes more normal. At the moment, you know, I'm thinking all the time of the lesson plans, scheme of work, etcetera, etcetera. I've got to do this and once that becomes done, then you know, perhaps pay more attention and focus to the standards. (February 2008)

Trainees all expressed concerns about pressures on time. Although they recognised the potential of using an ILP, immediate commitments to teaching and assessing students together with the demands of writing assignments and maintaining integrity in their classroom practices took priority over using it in anything other than a functional way. They were concerned with 'doing the necessary' to meet the formal requirements of the programme. This necessarily impinged on time that they might otherwise have spent on different and perhaps more fruitful, activities.

In this section we have demonstrated different ways in which the interpretation and enactment of policy have fed into teacher education practices. We have seen that 
those managers and tutors with positive experiences of mentoring tended to emphasise the primary importance of establishing a good personal relationship, of showing flexibility in being available and being responsive to the stated needs of the mentee, and in articulating those needs within the organisation. We heard about a range of ways in which mentoring types of support can occur very successfully informally (for example, in 'buddy' arrangements) and also occur informally within formal systems and structures. We found support among tutors for providing 'subject-specific' mentors, but in a way that recognised the prior experiences of each trainee teacher. References were made to the need for a mentor to be prepared to 'challenge' a mentee and how that related to the maintenance of 'high expectations'. Although subject knowledge and expertise was a contributory factor to the success of mentoring relationships, with trainee teachers able to draw upon the expertise of more experienced colleagues, the quality of their relationships with their mentors and other close working colleagues was more important.

\section{Conclusions}

There can be little doubt that the FE sector has benefited from greater government support and resources, particularly given the recent sustained increase over the last 20 years in demand for courses and programmes including teacher education programmes. However, rather than addressing structural questions and issues of resourcing which arise from that - including the systematic erosion of the conditions of service and pay of lecturers and the intensification of workloads - the emphasis has centred upon improving the quality of teaching and the performative systems and measures that can be used to address those problems. These changes in governance have not only been confined to the FE sector but have been mirrored elsewhere in the 
public sector where there has also been a dramatic shift away from professional discourses and practices of the old public sector towards the rhetorics of modernisation, competition, innovation and enterprise. The effects have both impacted at a macro structural and organisational level and the micro level as individuals have struggled to manage the effects of changing policy and curriculum reform into their practices.

All of the interviewees interpreted and rationalised their experiences and understandings of mentoring as part of their own life worlds. What we were able to observe as researchers (Shutz 1967), was a struggle to delineate the boundaries of their roles and responsibilities as they brought together the external and performative requirements with their own interpretations.

At one level the mentor role was aligned with that of a 'subject coach' or assessor who is solely responsible for the achievement of standards and for the assessment of those standards against fixed criteria. However many tutors and managers regarded the mentor role as formative and developmental, which placed them in a role that was potentially at odds with their assessment role.

If we consider the use of standards, we found a consensus that they are important but there was clearly a range of views of why they matter. Andrew and Claire saw them as an important feature of professional conduct while Dawn and Gill particularly emphasised their importance as expectations of performance consistent with a community of practice. However, when it came to the specific policy technology of ILPs, some tutors like Maggie put less emphasis on the them and more upon their response of the needs of the individual.

Colley (2003) found that mentees value relationships that they can choose and negotiate for themselves and that they use the opportunities provided to develop such 
relationships in constructive and creative ways. Colley warns that you cannot take for granted that a mentor will be willing, able or competent to fulfil a role that achieves particular outcomes for a mentee as set by an institution or organisation (Colley 2003, 159). We would agree that there are tensions between the formative and performative purposes of different models of mentoring - whether the emphasis is upon support for the learning and professional development of the trainee teacher, or whether the aim is to decide if a qualification and a licence to practice are to be awarded. The need for judgement of the latter purpose risks undermining the potential of the former. These were central issues as managers and tutors struggled to find the boundaries of their responsibilities and as trainees struggled to find a place in the process. Is the mentor role akin to that of a 'subject coach' or assessor who is solely responsible for the achievement of standards and for the assessment of those standards against fixed criteria? These tensions are exemplified below in the table:

Formative and performative models of mentoring (adapted from Tedder and Lawy 2009, 426)

\begin{tabular}{|l|l|}
\hline Formative model & Performative model \\
\hline Best undertaken in confidence & Necessarily public \\
development & Focussed on judgement of performance \\
Supportive through transitions & Concerned with standards \\
Profession-centred & Subject - centred \\
Suitable for all & Mainly for trainees \\
Emphasis on networks & Emphasis on individuals \\
Led by mentee & Led by mentor \\
\hline
\end{tabular}


The distinctions between formative and performative practice in the FE work environment resonates with the 'expansive-restricted' analytic framework found within the work of Fuller and Unwin (2004). Lucas and Unwin (2009, 431) have noted that 'many colleges are characterised by restrictive features of job design and work organisation', meaning that staff have limited responsibilities, are subject to continuous surveillance with their opportunities for autonomous action and decisionmaking limited. Citing evidence for this they point to 'a significant gap between the rhetoric of recent ITE [Initial Teacher Education] reforms and the reality experienced by many in-service trainees in FE colleges' (Lucas and Unwin 2009, 431).

One of the most significant differences between the school and the FE sector teacher education is that FE sector practices are not centred upon subject groupings, rather all trainees are located in a single grouping where they work with their tutors and other trainees across subject boundaries. Traditionally this approach has brought together trainees with different pedagogical interests and viewpoints and so has encouraged discussions about practice and learning that are inherently pedagogical. The recent introduction of the subject-based model of practice into the FE sector was occasioned because of its perceived success in 'raising standards' in the school sector and the failure of the FE sector to raise standards (Ofsted 2003, 2006; DfES 2004). Under this model teacher apprentices learn from master practitioners about their subjects (Lave and Wenger 1991). Pedagogy is reduced to a skill-set which in turn lends itself to a training model with its performative emphasis upon testing, surveillance and control. The testing of knowledge and skill-set with a clear emphasis on subject-pedagogy/specificity, has been used as a proxy for judging likely classroom performance based on performative and measurable criteria and standards. 
This is monitored through the trainees' ILPs to ensure that they meet the appropriate standards that will allow them to practice as teachers. This performative shift has served to redefine symbolic and material meaning both at an institutional level through the systematisation of regimes of accountability and also at a social level through the regulation and prescription of practice.

Systems and procedures are integral to the 'policy technology' and have been increasingly subject to regulation surveillance and management through bureaucratic and highly structured and low-trust systems of accountability that have become reified as 'ends-in-themselves'. Here outcome, assessment and accountability measurement provide the raison d'être for a set of often paper-based practices and procedures (Avis 2005; Ball 2008). But these systems of accountability only measure and assess that which is formally required and are ineffective at measuring the sometimes intangible qualities and pre-requisites of 'good' teaching. The shift away from formative and developmental approaches towards increasing regulation has been received with varying amounts of enthusiasm and commitment. There was a degree of scepticism about subject coaching where it is concerned only with technical issues of practice. Andrew for example was sympathetic to subject-specific mentoring that could address the particular pedagogic needs of his subject area. Others tutors, such as Angela and Claire, were less enamoured by changes in their role and the performative expectations and were more concerned with providing general support and guidance for their mentees.

The main argument of this paper has been centred upon issues of practice within FE teacher education the issues that have been raised are indicative of a more general reductionist trend within the public sector where externally measurable criteria and standards are now routinely used to measure performance and provide the basis for 
judgements of competence. In this respect the paper represent an antidote to the bland bureaucratic and atheoretical (or anti-theoretical) and performative commentaries concerned with systems and structures and the need to maintain and ensure standards and 'good' practice. The implications for practice are important for managers and tutors as they have sought to maintain a sense of equilibrium within a culture of compliance, managing and structuring their engagements within contemporary professional life. They are also however, perhaps more crucially important for the next generation of teachers whose judgements of worth and professional identities are being steered by a set of externally imposed bureaucratic, technologies, procedures and goals.

\section{Notes}

[1] The age of participation (RPA) is set to rise in England from age 16 to age 17 in 2013 and to age 18 in 2015. This will have far reaching ramifications for staff and students in the FE sector.

[2] Lifelong Learning UK (LLUK) is the Sector Skills Council responsible for the lifelong learning sector. It has devolved responsibility for standards in teacher training to Standards Verification UK (SVUK).

[3] The Learning and Skills Council (LSC) was established in 2001 and was abolished in March 2009. It was responsible for funding in the FE sector with a budget in excess of $£ 10$ billion. It has been replaced with the Young People’s Learning Agency and the Skills Funding Agency.

[4] Eleven Centres for Excellence in Teacher Training (CETTs) were established by the government through the Quality Improvement Agency (QIA) to address 
weaknesses in teacher training. The success of the initiative is based upon networks of providers supporting one another across further education, adult and community education and work-based learning.

[5] We have used the term trainee rather than student in order to avoid possible confusion between the trainee teachers and their students. The distinction between tutors and managers was less clear. We use the term manager when the member of staff concerned had a responsibility for quality, programme management or development of the teacher training programme. We also included staff in the managerial category who were interviewed because of their broader management responsibilities but were not directly involved in teaching on the programmes. 


\section{References}

Ainley, P., and B. Bailey. 1997. The business of learning. Staff and student experiences of further education in the 1990s. London: Cassell.

Alheit, P. 2005. Stories and structures: An essay on historical times, narratives and their hidden impact on adult learning. Studies in the Education of Adults 37, no. 2: 201-12.

Association of Colleges and the Further Education National Training Organisation. 2001. Mentoring towards excellence. Coventry: Learning and Skills Council.

Avis, J. 2005. Beyond performativity: Reflections on activist professionalism and the labour process in further education. Journal of Education Policy 20, no. 2: 209-22.

Ball, S. J. 2003. The teacher's soul and the terrors of performativity, Journal of Education Policy 18, No. 2: 215-28.

Ball, S. J. 2008. The education debate. Bristol: The policy press.

Clarke, J. and J. Newman. 1997. The managerial state. London: Sage.

Colley, H. 2003. Mentoring for social inclusion: A critical approach to nurturing mentor relationships. London: Routledge. 
Colley. H., D. James, and K. Diment. 2007 Unbecoming teachers: Towards a more dynamic notion of professional participation. Journal of Education Policy 22, no.2: $173-93$

Dale, R. 1989. The state and education policy. Milton Keynes: Open University.

Department for Education. 1992. Initial teacher training (secondary phase) London: Department for Education/Welsh Office.

Department for Education. 1993. The initial training of primary school teachers: New criteria for courses. London: Department for Education/Welsh Office.

Department for Education and Skills. 2004. Equipping our teachers for the future: Reforming initial teacher training for the learning and skills sector. London: The Stationery Office.

Edward, S., and F. Coffield. 2007. Policy and practice in the learning and skills sector: Setting the scene. Journal of Vocational Education and Training 59, no. 2: $121-35$

Evetts, J. 2005. The management of professionalism: A contemporary paradox. Paper presented at the Teaching and Learning Research Programme Seminar 5, King's College, London, 19 October.

Foucault, M. 1977. Discipline and punish. The birth of the prison. London: Penguin. 
Fournier, V. 1999. The appeal to 'professionalism' as a disciplinary mechanism Social Review 47, no.2: 280-307.

Fuller, A., and L. Unwin. 2004. Expansive learning environments: integrating organizational and personal development. In Workplace learning in context, ed. $\mathrm{H}$. Rainbird, A. Fuller, and A. Munro. London: Routledge. pp 126-144

Further Education National Training Organisation. 1999. Standards for teaching and supporting learning in further education in England and Wales. London: FENTO.

Gleeson. D., J. Davies, and E. Wheeler. 2005. On the making and taking of professionalism in the further education workplace. British Journal of Sociology of Education 26, no.4: 445-60.

Gleeson, D., and F. Shain. 1999. Managing ambiguity: Between markets and managerialism - a case study of 'middle' managers in further education. The Sociological Review 47, no.3: 461-90.

Hamilton, M. 2009. Putting words in their mouths: The alignment of identities with system goals through the use of Individual Learning Plans. British Educational Research Journal 35, no.2: 221-42.

Harrison, R., J. Clarke, and F. Reeve. 2003. Doing identity work: Fuzzy boundaries and flexibility in further education. Research in Post-Compulsory Education 8, no.1: 93-105. 
Institute for Learning. 2009. Guidelines for your continuing professional development (CPD). London: IfL.

James, D., and G. Biesta. 2007. Improving learning cultures in further education. London: Routledge.

Laker. A., J.C. Laker., and S. Lea. 2008. Sources of support for pre-service teachers during school experience. Mentoring and Tutoring 16, no.2: 125-40.

Lave, J., and E. Wenger. 1991. Situated learning: Legitimate peripheral participation. Cambridge: Cambridge University Press.

Lawy, R., and M. Tedder. (2009a) Meeting standards: Teacher education in the further education sector. What of the agency of teacher educators? Studies in the Education of Adults 41, no1: 53-67.

Lawy, R., and M. Tedder. (2009b) Further education initial teacher education in the learning and skills sector in the SW of England: ILPs, mentors and mentor training Exeter: University of Exeter and SWitch CETT.

Learning and Skills Council. 2005. Priorities for success: Funding for learning and skills. Coventry: LSC. 
Lifelong Learning UK. 2007. Further education workforce reforms. Explaining initial teacher training, continuing professional development and principals' qualifications in England. http://www.lifelonglearninguk.org/ittreforms/index.htm (accessed January 7, 2008)

Lifelong Learning UK. 2009 The workforce strategy for the further education sector in England 2007-2012. http://lluk.org/fe-workforce-strategy.htm (accessed November 18, 2009)

Lucas, N., and L. Unwin. 2009. Developing teacher expertise at work: in-service trainee teachers in colleges of further education in England. Journal of Further and Higher Education 33, no4: 423-33.

Nasta, T. 2007. Translating national standards into practice for the initial training of further education (FE) teachers in England. Research in Post-compulsory Education 12, no.1: 1-17.

Office for Standards in Education. 2003. The initial training of further education teachers - a survey. London: Ofsted.

Office for Standards in Education. 2006. The initial training of further education teachers - findings from 2004/05 inspection of courses leading to national awarding body qualifications. London: Ofsted. 
Shain, F., and D. Gleeson. 1999. Under new management: Changing conceptions of teacher professionalism and policy in the further education sector. Journal of Education Policy 14, no. 4: 445 - 62.

Shutz, T. 1967. Collected papers: Volume 1. The Hague: Martinus Nijhoff.

Steer, R., K. Spours., A. Hodgson., I. Finlay., F. Coffield., S. Edward., and M. Gregson. 2007. Modernisation and the role of policy levers in the learning and skills sector, Journal of Vocational Education and Training 59, no. 2: 175 - 92.

Tedder, M., and G.J.J. Biesta. 2009. Biography, transition and learning in the lifecourse: the role of narrative. In Researching transitions in lifelong learning, ed. J. Field, J. Gallacher and R. Ingram. London: Routledge. pp 76-90

Tedder, M., and R. Lawy. 2009. The pursuit of 'excellence': mentoring in FE initial teacher training. Journal of Vocational Education and Training 61, no.4: 413-29. 